\title{
Movie Media: Misrepresentation of Homosexual Characters Within Comedy Films Since the 80s Caused by Heterosexist Ideals in the Acting and Directing Process
}

\author{
Jordan D. Salyer-Gummoe ${ }^{1}$ and David Morton" ${ }^{1 \#}$ \\ ${ }^{1}$ Vacaville High School, CA, USA \\ \#Advisor
}

$\underline{\text { ABSTRACT }}$

Critical discourse analysis is a qualitative research approach used to study social inequalities, in which it creates the connection between social practices and the social context. The use of film analysis variables of non-discourse and discourse practices relating to this analysis approach was examined from one film representative of each decade: the 1980s, 1990s, and 2000s. The heterosexism found within the acting and directing process of films within the comedy genre while structuring a gay character in screenplay was examined through the research process by homing in on specific variables. The conducted study's research process involved multiple viewings of each movie: Victor/Victoria, Clueless, and Bridget's Jones Diary where 3 scenes were chosen from the film regarding variables such as materializations, speech, and actions that held correlation to the portrayal of a homosexual characters. By the film variables directly corresponding with the characterization, the research analysis demonstrated heterosexist actor's and director's choices throughout the filming process and their correlation to common stereotypes against homosexuals being drawn off of for comedic effect. Over the span of 3 decades, the use of stereotypes within homosexual movie media representation; although progressive towards inclusion, has strictly portrayed such characters in comical, non-serious scenes. It is with a comparison of the 1980s, 1990s, and 2000s take on gay portrayals that the founded extremity of the use of such common stereotypes was recognized as they continuously, negatively impact the LGBTQ community through the continuation of use constituting these portrayed personas as correct.

\section{Literature Review}

Starting in the mid-60s and following into the early 80s LGBTQ rights became an issue more relevant within society. This can be captured within the increased commonality of the cinema producing films with homosexual characters (Fisher 2007). This fell within the era of the vocal and visible gay rights movement; such as the gay liberation movement(Fisher 2007). With gay and lesbian characters gaining more screen time you'd hope to see various representations of their structurization and personality attributes, however gay and lesbian representation in films tend to routinely be seen in comedy movies with uncanny character similarities created through the writing of the characters as well as the actor's personal portrayal choices. Leaving us with the question of 'How has the movie industry's portrayal through the acting and directing process of creating homosexual characters within comedy films developed since the 80s?' To continue clearly understanding the topic some words must be defined:

- Discursive-enables you to explore the construction of meanings in human interaction, interpretive systems, and practices through which behavior is viewed 
- Linguistic-Scientific study of language involving the analysis of language form, language meaning, and language in context

As much progress has been made over the decades when it relates to the accurate representation of those with differing sexual preferences and orientations, properties of comedy films have yet to yield similar growth, "despite some changes in the status of gay men and lesbians in society, stereotypes regarding sexual orientation were similar to those seen in studies conducted 20 years ago"(Blashill, Powlishta 2009). Such reliance on stereotypes for comedic effect only indicates how much growth is yet to come in the movie industry. College professor Micheal Green exaggerates the importance of identifying the issue to his film students; in which comedy movies are continuously held to a different standard relating to stereotyping; while in recent dramas it is rare to depict such extreme stereotypes, comedies still are considered 'fair game'(Green 2013). Found in a preliminary study done by Gurrwitz and Marcus having 40 students rate a list of 77 traits in terms of whether they apply to homosexual men rather than straight and vice versa, male homosexuals tend to be perceived by a heterosexual society as less aggressive, poor leaders, gentle, passive, extremely clothes conscious, as well as undoubtedly theatrical (Taylor 1983). By defining the constrictions of society's version of the features of a gay man and creating concrete stereotypes that veer off as believing all gay men to be feminine and defined as having more outgoing, extreme characteristics it makes them a group perfectly targeted to fit in a theatrical setting of a comedy movie.

\subsection{Stereotype Representation}

The misrepresentation of gay characters within film subjects the LGBTQ community to stereotypes that have been built off of common misconceptions for years; such stereotypes establish the belief that those who sexually identify as gay or lesbian cannot be a real man or woman due to sexual preferences (Hill, Gibson 1998). Heterosexism has popularized the idea that gay men must be feminine because they are attracted to other males; similarly to a heterosexual female, or lesbians must be masculine because they are attracted to females; like a heterosexual male(Kite, Deaux 1987). Common stereotypes that have been applied to homosexuals within comedy films can be depicted through the categorization of 'queens' and 'dykes'. In this case, gay men referred to as queens tend to exemplify feminine traits such as higher-pitched voice, clothes with more girl-like qualities, as well as interests that may dominantly be stereotyped with relation to females. Lesbians characterized as 'dykes' exhibit more subtle masculine traits such as short hair or more man-like clothing such as baggy pants, suits, and button-ups (Hill, Gibson 1998). The representation of the 'queen' and 'dyke' stereotypes within films reproduces the norms on gendered heterosexuality indicating that the effeminate men and mannish women fall short of heterosexual norms, and is one version of the structuring opposition of sexuality differences (Hill, Gibson 1998).

A society dominated with heterosexual men and woman tends to idealize these stereotypes in which lesbian and gays are held under, and with the commonality of it also being illustrated in movies, such ideals continue to be further normalized and constituted as 'correct'. So much so that a theory developed by Austrian neurologist Sigmund Freud was the first to evolve the idea of why such stereotypes tend to be accurate, similarly mentioned by Marky Kite and Kay Deaux that the "...implicit inversion theory, derived from classic theories of sexuality" (Kite, Deaux 1987). This theory states that some young men and women come to identify so strongly with the opposite-sex parent that they take on his or her characteristics. Hence, these individuals become sexually attracted to same-sex others and also come to exhibit mannerisms and attitudes that are characteristic of the other sex(Kite, Deaux 1987) Freudian logic has been extremely harmful to the queer community because of the implications that sexuality is a choice/due to conditioning and therefore can be changed. These stereotypes developed by a heterosexual society play a key role in homosexual character misrepresentation through both directing and acting. When it relates to the structurization of gay characters a straight director or actor tends to draw from stereotypes for character inspiration. In a similar case, perceptual studies have shown that listeners' rating of the masculinity/femininity of a speaker's voice is correlated with their judgment of the speaker's sexual orientation: voices rated with higher femininity scores are more likely be judged as 
belonging to homosexual male speakers (and vice versa) ( Cartei, Reby 2012). The conducted study continued to compare the fundamental frequency and formant frequency parameters in speech of 15 actors experienced in playing homosexual and heterosexual characters in North American television. Results revealing, that actors playing homosexual male characters are characterized by raising fundamental frequency(higher pitch) as well as rasing format frequency(less baritone). The actors' frequency values approached those of a typical female voice (Cartei, Reby 2012).

\subsection{Research Method Overview}

Past research has yet to yield any understanding informing on the cause of misrepresentation of homosexual attributes due to specified film aspects; causing little to no change in homosexual stereotypes in the past 20 years(Blashill, Powlishta 2009). With this it has led me to use critical discourse analysis to focus on film variables allowing me to address the open gap in the field; falling under how homosexual characters are structured due to portrayals by straight actors and heterosexual stereotyping exemplified in the acting and directing process. These film aspects mentioned, will be analyzed through the use of discourse variables and relate to the cause of character misrepresentation. I will be performing a content film analysis of 3 randomly chosen films. Each film falls between the time period as early as the 1980s and as late as the 2000s, as well as appears under the comedy genre with one developed gay character. To thoroughly analyze scenes with varying gay portrayals I will utilize critical discourse analysis variables; allowing me to examine each scene's speech, actions, and materialisations. More specifically I will be examining tone of voice/what the character says, common interests or performed actions of the character, as well as their clothing and presentation within the film. My methods will be displayed in a data table as such:

\begin{tabular}{|l|l|l|}
\hline \multicolumn{1}{|c|}{ Movie Title } & \multicolumn{1}{c|}{ Time of Scene } & \multicolumn{1}{c|}{ Description } \\
\hline Speech & Ex- 54 minutes 27 seconds in & $\begin{array}{l}\text { Ex- "I love shopping" was said in a } \\
\text { higher-pitched tone of excitement } \\
\text { that can be identified as a girlish } \\
\text { squeal }\end{array}$ \\
\hline Materialisations & Ex- 1 hour 43 minutes in & $\begin{array}{l}\text { Depicted wearing a tight purple } \\
\text { tank top and skinny jeans }\end{array}$ \\
\hline Actions & Ex- 32 minutes 12 seconds in & Painting nails with female friends \\
\hline
\end{tabular}

My goal will be to create and demonstrate a correlation between heterosexism found in the writing and casting process of homosexual characters, and connect how gay misrepresentation in comedy films is created through the drawing off of stereotypes to structure a character. With my research, this issue can further be explored and related back to how film's linguistic and discourse variables play a role in the heterosexist ideals of creating what a homosexual character "should be" in the comedy genre.

\section{Methodology}

I conducted a film analysis of 3 randomly generated movies falling under two specific categories; genre: comedy and character inclusion of homosexual development. To analyze these movies, I performed a dispositive critical discourse analysis (CDA). Critical discourse analysis is a qualitative analytical approach used to critically describe and interpret the roles of discourse in legitimizing social inequalities, exploring connections between social practices and social 
context (Mullet 2018). Discourse studies focus on the use of text and language to expand on non-discursive and discursive practices (Gatling 2014).

To further past research I have chosen to examine the structuring of gay characters specifically when falling into comedy films through the acting and directing process, using CDA to create a relationship between non-linguistic and linguistic discourse variables within my analysis of homosexual characterization. The following movies will be viewed and analyzed for discourse criteria, Victor/Victoria produced March 19th, 1982, viewing character Caroll Todd played by Robert Preston, Clueless produced July 19th, 1995 viewing character Christian Stovitz played by Justin Walker, and Bridget Jones Diary produced April 13th, 2001 viewing character Tom played by James Callis (all portrayed/directed by straight actors).

Utilizing a critical discourse analysis within my educational research study is the optimal method in answering my research question. The alignment between my question and method is laid out as such: beginning with my research question it has been created to hone in on character development of homosexual characters throughout three decades, to view any change in the use of pushing heterosexist stereotypes onto men and women who differ in gender sexual preferences. Used to identify and prove the injustice within comedy films causing gay/lesbian misrepresentation; critical discourse analysis is an approach used to analyze, interpret and describe social prejudices and inequalities created by higher social constructs and media presentations (Mullet 2018). CDA's involvement in the interest of how social members are categorized provides my research with a basis to prove and legitimize social inequalities towards the LGBTQ community when referring to pushing stereotypical ideals in the film industry (Ainsworth, Hardy 2004 ). The prejudices and oppression of social groups in daily life are commonly reproduced through political/media discourses led by elitist groups leading to the reproduction of cultural misinterpretations in many forms(Mullet 2018); furtherly falling in alignment with my research goals. As to how CDA as a method will answer my question, we first must begin looking at how a film character is developed. In movies throughout many eras, characters are illustrated through what they say, how they act, their appearance, or interests. To examine film aspects and compare their similarities and differences from 1980 to the 2000s, we must begin with a starting point of what to look for. Dispositive discourse analysis provides a foundation for analyzing film aspects through the involvement of discourse variables such as text/speech, actions, and materialisations. The following discursive variables similarly align and categorize what is used to structure a movie character. Allowing me the opportunity to answer my research question through a dispositive analysis demonstrating a key relationship between aspects of film creation and character representations through non-linguistic and linguistic discourse practices.

\subsection{Research Procedures}

Choosing Films: I compiled a list of 15 movies for each decade; from the 1980s-1989, 1990-1999, and 2000s up. Each movie fell under two necessary criteria: released as a comedy film, as well as included a fully developed gay character. After further compiling the movies representative for each decade, I then correlated each movie with a given number that fell between the numbers of movies gathered (1-15). Following, I used Google's tool of a random number generator to determine the movies in which I would watch; minimum set at 1 and maximum set at 15. For the 1980s movie: \#4, for the 1990s movie: \#11, and for the 2000s movie: \#2.

CDA Data Collection: To conduct my analysis I began by fully viewing each movie at least 2 times to grasp the plot and themes. With a third viewing, I choose 3 scenes spaced out throughout the film to represent each variable of discourse; speech, actions, and materialisations. To identify which scenes will be chosen they must exemplify importance to the movie as well as be relevant to the specified discourse variable. To validify my choosing for each scene I have developed criteria on which to base my pickings:

Speech: something said that demonstrates importance to characters personality and/or development, could be an uncommon phrase in which specifically relates to the specified character or a differing tone of voice 
Actions: something in which the character does expressing hobbies or likes, as well potential relationship status with other characters

Materialisations: full depiction of characters clothing and style choice or any object within the scene that relates to use of or possession by the character.

The specific scenes chosen; fitting the developed criteria, were also identified as having the most notable impact on the plot and development of the character's personality attributes. All data will then be presented within the table depicted in my lit review, formatting the timing of the scene, the variable of discourse, as well as what was depicted or said within that particular scene that has the involvement of a discourse practice within film.

\subsection{Limitations}

When choosing the use of a film analysis and exploiting the method of dispositive critical discourse from the time period of 1980 to the 2000s many limitations of the effectiveness of my research must be addressed. By choosing a maximum of 3 films, it provides my research with a limited sample size of movies released throughout 30 years. With the inclusion of more films, it would allow me to assess various examples of how homosexuals are depicted in differing comedy films. As well as this, I was limited in providing only one example of each CDA variable per film. With these limits it is however that with popularized and well-defined stereotypes regarded against gays in comedy films,that further revelations that could have been provided by more data may not have needed to be noted, but lessened the strength of my argument due to the extremity of my research claims. Further drawbacks can relate to the process of the films being guided through a random generation process; the release dates of the films generated did not cover current or presently produced films. My research allows me a comparison of the stylistic acting and directing choices made from movies over 3 decades, but will not include the last 10 years of film. The limitations that went along with my data collection and research process although create supportive evidence for my claims cannot sufficiently back them up the extremes in which they have been presented.

\section{Analysis}

\subsection{Victor/Victoria}

The title Victor/Victoria is taken from the name of the female leads male and female personas used throughout the film. Set in 1934 France, this musical comedy follows the leading soprano Victoria Grant through her unsatisfied poverty-stricken life. By catching the attention of Toddy, a previously fired nightclub entertainer, during an audition leading her into the daze of Paris, show business as a nightclub performer being a "male" female impersonator (IMBd TV 1983). As an MGM studio-produced film released in 1981, 25 years later the movie is still said to be one of the most, "gay-positive movies ever made by a major studio...no other films match its balance of mainstream marketability and unflaggingly pro-gay positioning" in American cinema (Kregloe 2007).

The character Caroll Todd otherwise referenced as Toddy was first introduced at the beginning of the film with the director's choice of a cut scene depicting "Richard di Nardo, a young gay hustler, emerging from the bed of middle-aged Carroll Todd" (IMBd TV 1983). His characterization also followed with theatrical tendencies as he was portrayed with a love for music, singing, and broad performances. With his sexuality clearly developed as gay; he fell in align as Victoria Grant's manager as well as best friend with whom she maintained a platonic relationship with (Owens 2019). The movie demonstrated a life shared by this female and male duo in Paris show business with extremely close connections to each other in various non-romantic scenarios. Director Blake Edwards intertwined their 
lives and goals seamlessly but separated their romantic pursuits unless it was to key in on Victoria seeking comfort or advice from an empathetic 'Toddy'.

Caroll Todd's interests within this film as well as his sense of theatricality and flamboyance tend to not stray away from common cliches/stereotypes regarded against gay men. Director Edwards however decided to discuss Toddy's sexuality within the film both openly and frankly (Kregloe 2007). Actor Robert Patterson and Director Blake Edwards create Toddy's character with an unapologetic attitude towards his homosexuality, while expressing overwhelming positive sexuality acceptance (Kregloe 2007). In doing so they create a gay-positive film during a decade of furthering gay acceptance and media representation. However, noticeable stereotypical attributes through discourse variables in the film can be noticed as Caroll Todd's characterization of being "undoubtingly gay" leads to a character with a large personality. He is unshameful of wearing a women's nightgown, demonstrating empathy frequently, as well as pursuing his dreams of singing and stage performance. Despite this, in comparison with other comedy films depicting homosexuality, Victor/Victoria less frequently draws off of homosexual stereotypes and when doing so it is not in pursuit of comedic effect, but acceptance towards the personality attributes a gay man might demonstrate.

\begin{tabular}{|l|l|l|}
\hline \multicolumn{1}{|c|}{ Victor/Victoria } & \multicolumn{1}{|c|}{ Time of Scene } & \multicolumn{1}{c|}{ Description } \\
\hline Speech & $10: 35-10: 40$ & $\begin{array}{l}\text { "They think when they say Paree is } \\
\text { gay they mean that gay Paree is } \\
\text { 'gay'(jazz hands)" }\end{array}$ \\
\hline Materializations & $24: 30$ & $\begin{array}{l}\text { Wearing a dress as a nightgown } \\
\text { with a blanket draped over his } \\
\text { shoulders }\end{array}$ \\
\hline Actions & $1: 55: 40-1: 56: 00$ & $\begin{array}{l}\text { Comforts Victoria after dreadful } \\
\text { heartache of falling in love }\end{array}$ \\
\hline
\end{tabular}

At the beginning of the film Victor/Victoria at around 10 minutes, Caroll Todd addresses, "They think when they say Paree is gay they mean that gay Paree is 'gay',"(Victor/Victoria). He then gestures with jazz hands to signify the stereotype of the theatricality of gay men; providing a stark contrast with the rest of the scene in which Todd invalidates such common ideals, however his characterization of love for spotlight attention and music fall under various categorized stereotypical interests. The contrast used through the comparison of his speech vs. actions however functions as an advocate for a common theme of the movie in which his character is unapologetically gay. Director Blake Edwards established this character's sexuality in a straightforward way towards the audience. Although his interests lean towards stereotypical gay behavior it does so in a way which Todd's character attributes aren't satirized but pushed proudly constituting gay positivity, by not using his character presence for comedic cliches.

Assessing Caroll Todd's clothing we see him in various scenes in a suit similar to other male characters; at 24:30 his nighttime apparel, however, differs from what they are depicted wearing. The femininity of this "broadshouldered, baritone-voiced" (Kregloe 2007) character is demonstrated as he is portrayed wearing a women's nightgown; similar to Victoria's, as well as a blanket draped over his shoulders. This particular scene's clothing choice relates back to the stereotype of 'queen' in which a gay man demonstrates feminine characteristics, as it creates a connection between Todd's femininity through similarities in his clothing to Victoria's; however, this particular scene in the film contains no present comedic effects. Film Director Edwards illustrated the character's typical gay attributes of femininity through materialization of clothing choices but did so in a scene with little to no comedic value. In doing so, it naturalized the character's choice of apparel being more deviated towards feminine clothing. 
Director Edwards also used many differing film aspects relating to discursive and non-discursive variables to again naturalize the attributes related to heterosexually pushed gay stereotypes. Regarding Caroll Todd's character near the end section of the movie at 1:55:40-1:56:00, he is utilized as a comfort character for Victoria who is handling heartbreak and established using the "gay best friend" stereotype often incorporated for audience laughter. She turns to him as a friend for advice and his empathetic tendencies. Although this relates heavily back to common stereotypes, the use of emphasizing this attribute of the character is to demonstrate the deeper depths of his emotion breaking beyond comedy movie cliches. His empathy is a tool used to highlight the naturalization of a gay man exhibiting emotional depth in comparison to various comedy movies superficial gay characters in satirized scenes.

The film Victor/Victoria is one American film released during the 80s featuring a gay man and his stereotyped characteristics in a positive light towards movie media. The semi-musical film relies on lowbrow slapstick comedy scenes to advance the plot. By examining various film aspects regarding differing discourse/non-discourse practices such as dialogue, actions, and clothing choices it is identified that the character Caroll Todd tends to feature many notable personality traits regarding his theatrical portrayal. Whether it relates to his melodramatic personality, feminine clothing choices, and womanly nature featuring an empathetic depth of his emotions, the film depicts scenes that showcase each aspect of his characterization relating to the typical 'queen' cliche however not involving comical satirization. Director Blake Edwards and actor Robert Patterson through the creation of character Todd's character identified common elements that stereotype a homosexual man and used them for non-satirized effects to naturalize and frankly address homosexuality, androgyny, and queer identity.

\subsection{Clueless}

Clueless released 1995; according to the synopsis published by Intermittent Mechanism, it "is a coming-of-age tale that traces the development of wealthy L.A. teen, Cher Horowitz...as she searches the glitzy world around her for emotional substance and meaning” (Boustany, Veiga, Nagler, Horwath 2020). This film is a 1990's classic take on drama and comedy, whilst it delivers themes of morality towards the target audience of adolescent teens by, "poignantly presenting friendship and empathy in an unlikely setting" (Boustany, Veiga, Nagler, Horwath 2020). Director Amy Hecklering delivered the comedic effects of this hit film with the use of extreme stereotypes and emphasis on Cher's blissful ignorance seen through her various character interactions.

By focusing on Cher's interactions, we are introduced to the character Christian Stovitz played by Justin Walker. Christian is a transfer student seen later in the film as he arrives in Mr.Hall's debate class(IMBd TV 1995). Immediately after, he becomes a character lusted by through a romantic pursuit of the main lead. Director Amy Hecklering further into the film dramatized the release of the idea that Christian's character was gay, after the many instances of denied romantic interactions with Cher. With the representation of this prominent homosexual character with zero sexual interest in the lead, they both maintain a genuine friendship (IMBd TV 1995). Developing this character forwards in the status as a "best friend" it is soon pronounced in various film scenes his interests in; clubbing, shopping, fashion, art, and old movies (Sarkisian 2020).

Relating to the characterization of Christian Stovitz, many of his interests decided by the director Amy Heckerling as well as actor Justin Walker's portrayal choices are related back to homosexual cliches. These "worn, tiresome, and unimaginative" tropes used by many films of this era are seen within the discursive and non-discursive practices that are connected to various film aspects (Sarkisian 2020). Through Hecklering's choices, Christian's stereotypical representation can be materialized down to the mere looks of his character and how he physically appears to the audience. Similarly, through Justin Walker's presentation of dialogue and physical gestures, his posture demonstrates the typical theatrical flamboyance gay men exhibit in film. 


\begin{tabular}{|l|l|l|}
\hline \multicolumn{1}{|c|}{ Clueless } & \multicolumn{1}{c|}{ Time of Scene } & \multicolumn{1}{c|}{ Description } \\
\hline Speech & $1: 08: 08-1: 08: 15$ & $\begin{array}{l}\text { "I have a question; the jacket, is it } \\
\text { James Dean or Jason Priestley?" }\end{array}$ \\
\hline Materialistaions & $54: 16$ & $\begin{array}{l}\text { Wears a black turtleneck w/ sun- } \\
\text { glass(indoors) tucked into black } \\
\text { pants with a plaid suited blazer }\end{array}$ \\
\hline Actions & $51: 36-51: 41$ & $\begin{array}{l}\text { Struts into the house and does a spin } \\
\text { w/ arm wide open }\end{array}$ \\
\hline
\end{tabular}

The dialogue spoken by Christian Stovitz's character in the film at 1:08:08-15 deviates towards typical stereotypes through the use of the linguistic variable: speech. Stovitz specifically states, "I have a question; the jacket, is it James Dean or Jason Priestley?" (Clueless) Common homosexual tropes familiarize the idea of gay men being 'extremely clothes conscious'. With the use of Christian's statement in the character dialogue; right after the reveal of his sexuality, Director Heckerling validates such by pushing this example of typical gay sex-role behavior; in which they participate in "woman things" with their straight female friends. The comparison Christian makes between two large actors James Dean and Jason Priestley's style while shopping is a small detail in his dialogue that further verifies his clothes-conscious behavior as he is detail-oriented enough to recognize the difference between their clothing styles.

Christian's gay tendencies within this film relating back to stereotypically pushed beliefs in comedy movies can also be materialized down to his personal, stylistic clothing presentation. Clueless presents various characters with many differing aesthetics; during one scene at 54:16 Stovitsz is seen wearing a black turtleneck tucked into black pants, with a plaid suit blazer, as well as sunglasses. The use of a turtleneck is not commonly seen on many straight male characters within various comedy films as well as the sunglasses being worn indoors have no practical use; so it can be assumed each item is used simply for his fashion display. With this, all the clothing choices made for Stovitz characters relate back to a "fashionista" stereotype typically labeled on feminine characters.

During the scene, 51:36-51:41 Christian's character struts into the house of the main lead Cher Horowitz. The audience views him as he continues walking and does a spin with his arms wide open. With body language and movement playing largely into the structurization of film characters; it can be assumed that the intention of his actions was to draw the attention and eyes of the room on him. His movement plays into the cliche of being attention-seeking and having a deep presence of theatricality. The use of this non-discursive practice exemplified by Justin Walker's portrayal choices demonstrates his character's melodramatic attitudes that play off of the previously mentioned "queen" stereotype.

The 1990's film Clueless was one of few involving a fully developed gay character and was relatively progressive towards homosexuals being captured within movies. Christian Stovitz in the movie was reproduced as a stereotypical gay man. It is identified in various scenes, common misconceptions assumed about all homosexual men is one aspect in the structuring of Christians character from his detailed fashion sensibility to his love for arts, as well as his flamboyant, attention-grabbing behavior his character plays in various scenarios: portraying him in a non-serious, comical light as the gay best friend.

\subsection{Bridget Jones Diary}

Produced in 2001, Bridget Jones Diary topped charts in the UK its first weekend, in comparison to other British films at the time (Maddison, Storr 2004). The film based on a diary follows 30-year-old Bridget Jones who comes to the realization of the changes she must make to her life. On New Year's Eve she makes a promise to herself to get her act 
together; consisting of losing weight, smoking/drinking less, and finding a perfect boyfriend (IMBd TV 2001). This comedy film consists of romance with adult humor and plots while playing on the thematic connection to self-improvement (Wycoff 2017). The film adopts the use of satire and realism through its characters for comedic effect; this can be seen through the main character Bridget, her two love interests Mark Darcy and Daniel Cleaver, as well as her inner circle Sharon, Jude, and Tom.

Focusing on the character Tom played by James Callis, he is characterized as Bridget's gay best friend as well as "one of the girls". As a one-hit-wonder, he consistently prides himself on his past music career. Director Sharon Maguire develops his outward presentation carefully throughout the film as his character is seen with many stylistic clothing choices, but his main role developed into a friend-like counselor aiding Bridget's Jones many life burdens regarding work, appearance, and romance. Though seen in the film his presence isn't frequent unless regarding scenes involving witty banter, girl's nights, as well as Bridget's need for friendly advice.

The structure of Tom's character stands in for a stark contrast in comparison of each individual character's sexuality and representation of feminine homosexuality. While heterosexuality in the film remains untouched and simply naturalized, Tom's presence has become tokenistic and disenfranchised (Maddison, Storr 2004). The distinct nature of Tom's actions in the film contrasted with the other characters provides comedic relief with the use of homosexuality as satire. Director Maguire as well as actor James Callis satirize Tom's sexuality through the use of the nondiscourse and discourse variables found within the film. Seen similarly in the two previously researched movie characters, he is portrayed with an extravagant personality as well as a love for clothes and music. His interests remain similar to those found in stereotypically pushed ideals as his theatrical behavior is depicted within scenes through his dialogue, as well as his femininity through physical body orientation.

\begin{tabular}{|l|l|l|}
\hline \multicolumn{1}{|c|}{ Bridget Jones Diary } & \multicolumn{1}{|c|}{ Time of Scene } & \multicolumn{1}{c|}{ Description } \\
\hline Speech & $16: 20-16: 26$ & $\begin{array}{l}\text { "Yes,yes it was me. 9 years ago no } \\
\text { plans to record anything else, thank } \\
\text { you so much" }\end{array}$ \\
\hline Materialistaions & $1: 03: 00$ & $\begin{array}{l}\text { Wears a red turtleneck as main } \\
\text { clothing piece w/ brown leather } \\
\text { jacket draped over }\end{array}$ \\
\hline Actions & $10: 02-10: 10$ & $\begin{array}{l}\text { Cigarette held between index and } \\
\text { middle finger while daintly moving } \\
\text { to and from his mouth w/ seductive } \\
\text { glare. }\end{array}$ \\
\hline
\end{tabular}

Beginning with non-discourse content found within Bridget Jones Diary, we examine a scene taking place in a crowded restaurant. In this scene, the various characters are depicted to be Bridget's close inner circle having a discussion over the rules she must follow when attending her next social occasion centered around her company's current book publication. The scene switches between each character participating in providing Bridget with essential advice on her behavior, clothing, and formal communication skills. At the time stamp 16:20, an older gentleman sitting at a nearby table turns around to address the group's inappropriate conversation and jokes for the general setting. However, within this scene, Director Maguire illustrated Tom's character turning around to engage saying, "Yes, yes it was me. 9 years ago no plans to record anything else, thank you so much."(Bridget Jones's Diary). By including Tom's assumption that this extra character chose to speak to him because of his 'impactful' past in music, it demonstrates traits within his characterization such as his flamboyant tendency to attract all attention to himself with his various confident but egotistical distinctions. 
One variant regarding homosexual stereotypes is the assumption that most gay men possess a love for clothing or style, as their characteristics are depicted as wanting to present themselves in eye-catching, dramatic means. At time stamp 1:03:00 relating to materialisations and clothing choices controlled by the director, Tom's character was dressed wearing a red turtleneck and brown leather jacket draped over his shoulder. Although not uncommon for heterosexual men to possess such style turtlenecks are an uncommon clothing piece seen worn by straight men in movies, but are utilized in comedy films to depict the stereotype of a "fashion lover" relating back to their commonality of continuously drawing off stereotypes to gain the desired effect.

Smaller details throughout the movie based on personal artistic choices of Tom's character portrayal decided by actor James Callis present unrecognized, but impactful effects on his movie representation. Small physical adjustments of the way a character moves or positions themselves express attitude through body language. At time stamp 10:02-10 James Callis placed his cigarette that Tom's character held in between his middle and index finger, moving two and from his mouth with a sensuous glare. The placement of his cigarette was expressed as a more feminine attribute as various straight male characters within the film held their cigarette between their thumb and pointer finger. These types of positionings were used throughout the film as small indicators to whether each character was portrayed with more dominant male or feminine features based on their nonverbal behaviors.

Tom's character placement within the film stands in for the representation of homosexuality, although it has frequent visibility it was not structurally equivalent to the presence of heterosexuality. The use of the film's discursive variables implements various typical gay jokes and stereotypes. The simplicity of this gay character's purpose stands in for the presence of "the gay best friend" and being "one of the girls". Elements of the characterization of Tom connect to his overdramatized dialogue and gaudiness, fashionable clothing style, and feminine body movements. The film Bridget Jone's Diary represents feminine homosexuality but utilizes their gay character strictly in scenes with desired comical effect; in which Tom's attention-grabbing behavior takes presence as a tokenistic cliche that maintains a laughability factor. The film relies on the presence of homosexuality for scenes to have a humorous effect, but naturalized heterosexuality remaining untouched throughout the film even through the creation of scenarios desiring the arousal of laughter from the audience.

\section{Conclusion}

Overall, all through my analysis, we see that by progression over 3 decades extreme stereotypes against homosexuals have worsened in comedy films. Within these films, the presence of straight actors and directors makes it more likely to draw off stereotypes for characterization to reach desired comedic effects. The 1980s; normalized attributes of gay men found within stereotypes by placing emphasis on them in non-satirized scenes. This is most likely due to the popularity of gay rights movements at the time as it was an era pushing gay positivity. While looking into the 1990s, the film integrates various stereotypical ideas that apply to their homosexual character and do so in a way to highlight his correlating characteristics. They mainly used these stereotypes to characterize the present homosexual character; Christian Stovits, which played the role in developing his position as the main leads gay 'best friend'. Although it had some comedic value, his character in numerous scenes remained with little emphasized, satirical use compared to Cher's laughable ignorance. However, the 2000s was the film with the most pronounced use of gay stereotypes that reached another level of extremity. The film's character remained solely to represent feminine homosexuality and theatricality through his presence as an utterly gay, tokenistic cliche. And with this, by using critical discourse variables that correlated with film aspects I am able to analyze this change in stereotype portrayals that happened through the acting and directing process in comedy films, over the progression of 3 decades from the 1980s through 2000s. In relation, my analysis recognized the increased severity of gay stereotypes progression over the 30 years when the development of structuring a homosexual character is placed in the hands of heterosexual actors and directors. With the commonality of using misconstrued stereotypes in comedy films, it begins to constitute inaccurate representations being applied to the general population of the LGBTQ community giving no variety to how they are viewed by society in movie media. 


\subsection{Implications}

Through the conduction of my research, it is a notable advancement forward in gaining attention to the targeting of homosexuals, portraying them strictly in a comical light. By pushing characters commonly into humorous scenarios it creates a gateway of character interpretation, favoring the use of extreme stereotypes for hysterical effect in screenplay. With films demonstrating the use of these habitual and cliche stereotypes the LGBTQ community is open to the negative opinions regarding their sexualities media presence in film favoring homophobic ideals. Statements regarding this issue, similarly represented in my research, must be popularized to gain the attention of the general media and raise the issue of the need for change in normalized societal stereotypes. By doing so we can reach and inform society as well as film directors, writers, and actors in the issue regarding their use of the LGBTQ community's comical, stereotyped representation in movie media.

\subsection{Further Research}

Moving forwards with the advancement for future research concerning movie media we must analyze what else can be addressed. My research specifically targets three discourse variables: speech, actions, and materialisations to compare the characterization of homosexual characters in films and their relation to frequently used stereotypes drawn off of by heterosexual actors and directors. To further my ideas, the aspects of my research must be expanded on. This includes the general sample size of films per decade being more than one, as well as a covering presently produced films from 2010-2020. The discourse variables within my research may also be altered and hone in on more specific film aspects in future works; such as body language and tone of voice that hold a direct connection. Disregarding the specific changes that must be made to my data collection and methods, a related research topic that can furtherly be addressed is the comparison between gay and straight actors and their independent take on how to portray a character's sexualities.

\subsection{Acknowledgements}

With the completion of this research, I thank teacher David Morton. Through providing various outlines and generalized setups for my research progression, he implemented himself as a teacher and advisor. The opportunity to apply for the class of AP research and with his guidance has allowed me to create and publish my own works. It is with this that the students within my class; giving no specific names, have peer graded and reviewed my paper through the different stages of development. I could not be more grateful to my class, my teacher, and the Journal of Student Research for the possibility and outcome given to me after much progress and final completion of my research paper.

\section{Bibliography}

Ainsworth S. , Hardy C. (2004) Critical discourse analysis and identity: why bother?, Critical Discourse Studies, 1:2, 225-259

Blashill, A.J., Powlishta, K.K. (2009)Gay Stereotypes: The Use of Sexual Orientation as a Cue for Gender-Related Attributes. Sex Roles 61, 783-793

Boustany, B., Veiga, W., Nagler, E., \& Horwath, G. (2020). The ultimate "MAKEOVER" In Clueless: MORALITY hidden in drama. Intermittent mechanism.

Cartei, V., Reby, D.(2012) Acting Gay: Male Actors Shift the Frequency Components of Their Voices Towards Female Values When Playing Homosexual Characters. J Nonverbal Behav 36, 79-93 (2012) 
Fisher, Deborah A. (2007) "Gay, Lesbian, and Bisexual Content on Television: A Quantitative Analysis Across Two Seasons.” Journal of Homosexuality, vol. 52, no. 3/4 pp. 167-188.

Gatling, Margaret, (2014). "Representations of Middle Age in Comedy Film: A Critical Discourse Analysis." Qualitative Report, vol. 19, no. 12, pp. 1-15. EBSCOhost,

Green, Michael.(2013) "Screenwriting Representation: Teaching Approaches to Writing Queer Characters." Journal of Film and Video, vol. 65, no. 1-2, pp. 30-42.

IMDb TV(1983). Victor/Victoria.IMDb

IMDb TV. (1995). Clueless.IMDb

IMDb TV (2001). Bridget Jones's Diary.IMDb.

Hill, John \& Gibson, Pamela(1998), The Oxford Guide to Film Studies, Oxford: Oxford University Press: 135-147

Kite, Mary E., \& Deaux, Kay.(1987) "Gender Belief Systems: Homosexuality and the Implicit Inversion Theory.” Psychology of Women Quarterly, vol. 11, no. 1, p. 83.

Kregloe, K. (2007). "Victor / Victoria": 25 Gay years later. Logo.

Maddison, S., \& Storr, M. (2004). The Edge of Reason: The Myth of Bridget Jones. Rodopi.

Mullet, D. R. (2018). A General Critical Discourse Analysis Framework for Educational Research. Journal of Advanced Academics, 29(2), 116-142.

Owens, M. (2019). The Hilarious, Beautiful Soul of Victor/Victoria. Indiana University Cinema.

Sarkisian, J. (2020). 9 movies that got their LGBTQ representation completely wrong. Insider.

Taylor, Alan. (1983) "Conceptions of Masculinity and Femininity as a Basis for Stereotypes of Male and Female Homosexuals." Journal of Homosexuality, vol. 9, no. 1, pp. 37-53.

Taylor, Alan. (2012) Spinsters and Singletons: Bridget Jones's Diary and its Cultural Reverberations. In: Single Women in Popular Culture. Palgrave Macmillan, London.

Van Dijk, T. A. (1993). Principles of Critical Discourse Analysis. Discourse \& Society, 4(2), 249-283.

Van Dijk, T. A. (1995). Aims of Critical Discourse Analysis, Japanese Discourse Vol 1. 17-27

Wycoff, B. (2017). Novel analysis: Bridget Jones's Diary (Helen Fielding). Bulb. 